\title{
Lead Time Reduction using Six Sigma Tools
}

\author{
B. Karthick ${ }^{1 *}$, Arun Kannan ${ }^{1}$, S. Manoj Kumar ${ }^{2}$ and S. Nirmal ${ }^{3}$ \\ 'Department of Mechanical Engineering, SNS College of Technology, Coimbatore - 641035, \\ Tamil Nadu, India; karthickb.shelan@gmail.com \\ ${ }^{2}$ Department of Mechanical Engineering, Bannari Amman Institute of Technology, \\ Sathyamangalam - 638401, Tamil Nadu, India \\ ${ }^{3}$ Department of Mechanical Engineering, EASA College of Engineering and Technology, \\ Coimbatore - 641105, Tamil Nadu, India
}

\begin{abstract}
The lean manufacturing is a systematic method for waste minimization. Lean techniques are applied in automobile service centers to create the easy, simple work environment and to improve customer satisfaction. Lead time is the time spent between the original customer order and final delivery of the vehicles. In the bike manufacturing company, its goal is to be a consumer brand, the company has to provide best service experience to their customers, and they operate service factories. They require minimum lead time, low cost and high customer service level to survive. In this project we analyze service factory and identify the root cause for the problem in service center. We implemented 5s methodology, value stream mapping to reduce the tools and spares searching time and to improve the working environment and also we had implemented quality deployment function to improve customer satisfaction. By implanting these lean methodologies and six sigma tools we reduced the lead time and improved customer satisfaction.
\end{abstract}

Keywords: Lean Time Reduction, Six Sigma, VSM

\section{Introduction}

The service sector is concerned with the soft part of the economy; where people render their time, skills and technical know-how to enhance productivity and performance. Producing services require relatively less of natural capital but more of human capital than agricultural or industrial goods. In line with the global trend, service sector in India has also grown rapidly in the last decade. Its growth has in fact been higher than the growth in agriculture and manufacturing sector. It now contributes around 51 percent of GDP.

\subsection{The History of Six Sigma}

The roots of Six Sigma as a measurement standard can be traced back to Carl Friedrich Gauss (1777-1855) who introduced the concept of the normal curve. Six Sigma as a measurement standard in product variation can be traced back to the 1920's when Walter Shewhart showed that three sigma from the mean is the point where a process requires correction. Many measurement standards (Cpk, Zero Defects, etc.) later came on the scene but credit for coining the term "Six Sigma" goes to a Motorola engineer named Bill Smith. (Incidentally, "Six Sigma" is a federally registered trademark of Motorola).

In the early and mid-1980s with Chairman Bob Galvin at the helm, Motorola engineers decided that the traditional quality levels- measuring defects in thousands of opportunities- didn't provide enough granularity. Instead, they wanted to measure the defects per million opportunities. Motorola developed this new standard and created the methodology and needed cultural change associated with it. Six Sigma helped Motorola realize powerful bottom-line results in their organization- in fact, they documented more than $\$ 16$ Billion in savings as a result of our Six Sigma efforts.

${ }^{*}$ Author for correspondence 
Since then, tens of thousands of companies around the world have adopted Six Sigma as a way of doing business. This is a direct result of many of America's leaders openly praising the benefits of Six Sigma. Leaders such as Larry Bossidy of Allied Signal (now Honeywell), and Jack Welch of General Electric Company. Rumour has it that Larry and Jack were playing golf one day and Jack bet Larry that he could implement Six Sigma faster and with greater results at GE than Larry did at Allied Signal. The results speak for themselves.

Six Sigma has evolved over time. It's more than just a quality system like TQM or ISO. It's a way of doing business. As Geoff Tennant describes in his book Six Sigma: SPC and TQM in Manufacturing and Services: "Six Sigma is many things, and it would perhaps be easier to list all the things that Six Sigma quality is not. Six Sigma can be seen as: a vision; a philosophy; a symbol; a metric; a goal; a methodology". Since years the practice of lean and six sigma was adapted individually to focus on waste reduction and quality as shown in Figure 1.

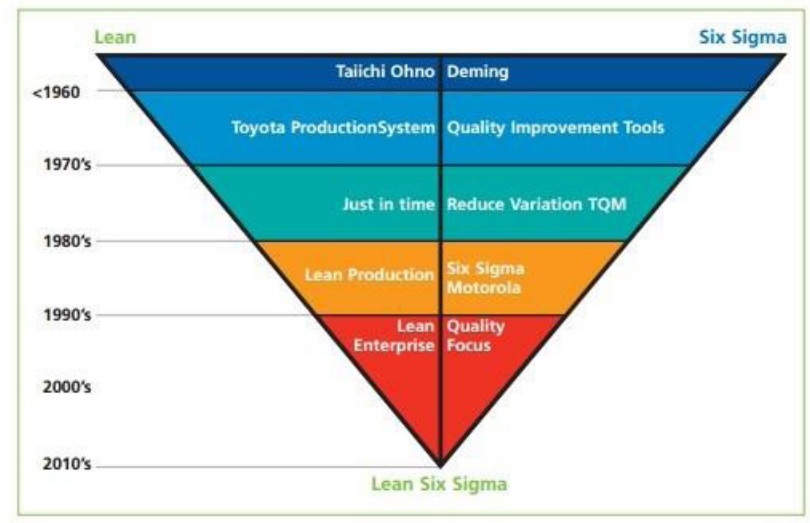

Figure 1. Origin of lean and six sigma.

\subsubsection{Concept of Six Sigma}

Six Sigma is the on-going effort to continually reduce process and product variation through a defined project approach. Six sigma is an effective approach which plays various roles in as a

- Philosophy

- Metric

- Methodology

- A Management system

\subsection{Lean}

Lean Manufacturing, also called Lean Production, is a set of tools and methodologies that aims for the continuous elimination of all waste in the production process. The main benefits of this are lower production costs, increased output and shorter production lead times.

\subsubsection{History of Lean}

Many of the concepts in Lean Manufacturing originate from the Toyota Production System (TPS) and have been implemented gradually throughout Toyota's operations beginning in the 1950's. By the 1980's Toyota had increasingly become known for the effectiveness with which it had implemented Just-In-Time (JIT) manufacturing systems. Today, Toyota is often considered one of the most efficient manufacturing companies in the world and the company that sets the standard for best practices in Lean Manufacturing. The term "Lean Manufacturing" or "Lean Production" first appeared in the 1992 book 'The Machine that Changed the World'.

Lean Manufacturing has increasingly been applied by leading manufacturing companies throughout the world, led by the major automobile manufactures and their equipment suppliers. Lean Manufacturing is becoming an increasingly important topic for manufacturing companies as they try to find ways to compete more effectively against competition.

\subsubsection{Principles of Lean Service}

The lean manufacturing philosophy, strongly disseminated by Taiichi Ohno, is based on principles that guide the "lean thinking". According to Womack \& Jones (2003), the principles of lean manufacturing are five, namely: value specification, value stream mapping, flow optimization, pull production system and perfection or continuous improvement.

For Nascimento \& Francischini (2004), the definition of lean service is a standardizable system of service operations made up only by activities that generate value for customers, focusing on explicit tangibles and aiming to meet the customers 'expectations for quality and price.

For Bowen \& Youngdhal (1998), the great similarity with the Womack's model is to generate production 
flow process in services and also use pull systems by the customer. Hariram VR, Karthick B (2017), Lean tools like Value Stream Mapping and Kaizen were used in the fabrication and tool rooms to improve the production and reduce the waste and Non value added activities.

\subsubsection{Objectives of Lean Manufacturing}

More specifically, some of the goals include;

Defects and Wastage- Reduce defects and unnecessary physical wastage, including excess use of raw material inputs, preventable defects, and costs associated with reprocessing defective items, and unnecessary product characteristics which are not required by customers.

Cycle Times- Reduce manufacturing lead times and production cycle times by reducing waiting times between processing stages, as well as process preparation times and product/model conversion times.

Inventory Levels- Minimize inventory levels at all stages of production, particularly works-in-progress between production stages. Lower inventories also mean lower working capital requirements.

Labour Productivity- Improve labour productivity, both by reducing the idle time of workers and ensuring that when workers are working, they are using their effort as productively as possible (including not doing unnecessary tasks or unnecessary motions).

Utilization of Equipment and Space- Use equipment and manufacturing space more efficiently by eliminating bottlenecks and maximizing the rate of production though existing equipment, while minimizing machine downtime.

Flexibility- Have the ability to produce a more flexible range of products with minimum changeover costs and changeover time.

\subsubsection{Guiding Principles for Lean Management Include:}

- Defining value from the standpoint of the end customer.

- Identifying each step in a business process and eliminating those steps that do not create value.

- Making the value-creating steps occur in tight sequence.

- Repeating the first three steps on a continuous basis until all waste has been eliminated.
Many have claimed that "lean" is not a buzz word; nor is it only a cost reduction technique. In fact, proponents of "lean" often regard it as one of the most important strategies for business to achieve world class performance by doing more with less.

\subsection{Lean Six Sigma}

Lean Six Sigma is a two staged business approach to continual improvement which focuses on reducing waste and product variation from manufacturing, service or design processes as shown in Figure 2.

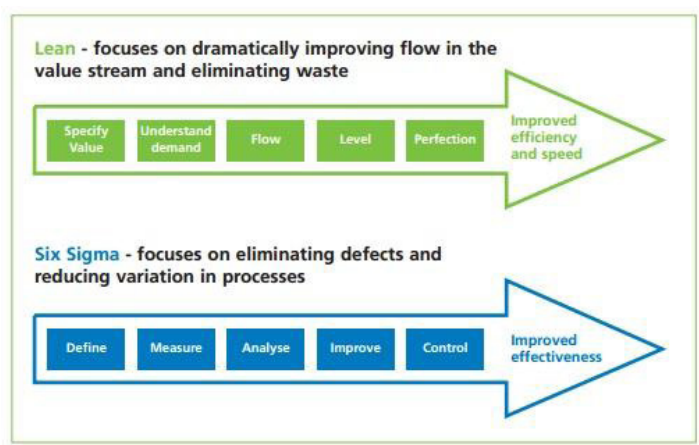

Figure 2. Flow of lean and six sigma.

Lean refers to maximizing customer value and minimizing waste; creating more value for customers with less wasted resources. Six Sigma is the on-going effort to continually reduce process and product variation through a defined project approach.

Combined, the two approaches drive continual improvement, building a philosophy that is the foundation of all effective management systems and any business that wants to grow and progress for the future.

Lean and Six Sigma complement each other. Lean accelerates Six Sigma, delivering greater results than what would typically be achieved by Lean or Six Sigma individually as shown in Figure 3. Combining these two methods gives a comprehensive tool set to increase the speed and effectiveness of any process within your organization - resulting in increased revenue, reduced costs and improved collaboration.

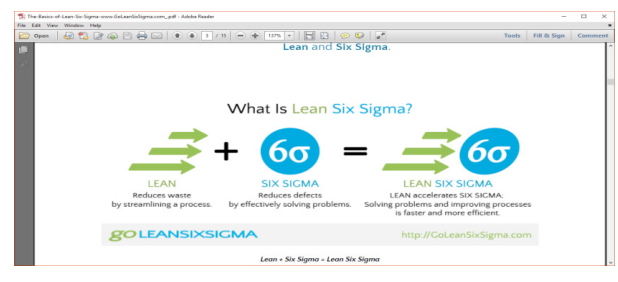

Figure 3. Lean six sigma. 


\subsubsection{The Five Steps of Good Maintenance- 5s}

In Japanese, $5 \mathrm{~S}$ is the short form of five words which present the concept of good maintenance.

The definitions and significance of the five words are given below:

- SEIRI- Sorting- making the difference between necessary and useless things in GEMBA, giving up the useless ones.

- SEITON- Ordering/Arrangement- the ordering of all the items after SEIRI.

- SEISO- Cleaning and disturbance detection- the working areas/equipment will be clean.

- SEIKETSU- Standardizing- the extension of the cleaning concept to each individual alongside with the continuous practice of the three steps 3S.

- SHITSUKE- Disciplining- getting self-discipline and getting used to be each involved in the $5 \mathrm{~S}$ actions through standard application.

\subsection{Metric}

The six sigma metric system states a process to be in six sigma there can be a 3.4 DPMO only i.e. a process with 99.9996\% defect free as in Table 1.

Table 1. Sigma level

\begin{tabular}{|l|l|l|l|}
\hline $\begin{array}{l}\text { Sigma } \\
\text { Performance } \\
\text { Level }\end{array}$ & $\begin{array}{l}\text { Defects per } \\
\text { Million } \\
\text { Opportunities }\end{array}$ & $\begin{array}{l}\text { Process } \\
\text { Yield }\end{array}$ & $\begin{array}{l}\text { Estimated } \\
\text { cost or } \\
\text { Poor } \\
\text { Quality }\end{array}$ \\
\hline $1.0 \sigma$ & 670000 & $33 \%$ & $>40 \%$ \\
\hline $2.0 \sigma$ & 308537 & $69.2 \%$ & $30-40 \%$ \\
\hline $3.0 \sigma$ & 66807 & 93.32 & $20-30 \%$ \\
\hline $4.0 \sigma$ & 6210 & $99.38 \%$ & $15-20 \%$ \\
\hline $5.0 \sigma$ & 233 & $99.9767 \%$ & $10-15 \%$ \\
\hline $6.0 \sigma$ & 3.4 & $99.99966 \%$ & $<10 \%$ \\
\hline
\end{tabular}

\subsubsection{Defect Rate}

When a process or characteristic doesn't perform within its specifications, it is considered defective; in other words, it produces a noncompliant condition called a defect. Automatically defining a defect as a noncompliance with specifications may seem overly simplified. Just because a characteristic exceeds a specification doesn't necessarily mean that the system it's part of will break or stop functioning.

\subsubsection{Defects per Unit}

A unit may be a discretely manufactured product or an invoice that crosses your desk. Whatever it is you do, in Six Sigma it's called a unit. A basic assessment of characteristic or process capability is to measure the total number of defects that occur over a known number of units. Then transform this measurement into a calculation of how often defects occur on a single unit

$$
D P U=\frac{\text { NUMBER OF DEFECTS OBSERVED }}{\text { NUMBER OF UNITS ANALYSED }}
$$

\subsubsection{Defects per Opportunity}

Defects per Opportunity (DPO) Defects per Opportunity is the probability of units produced with zero defects by the process. One part or unit may have as low as one opportunity for a defect or it may have infinite opportunities for defects.

$$
D P O=\frac{\text { DEFECTS }}{\text { TOTAL NUMBER OF OPPURTUNITIES }}
$$

\subsubsection{Defects per Million Opportunities}

A defect can be defined as a nonconformance of a quality characteristic. DPMO is stated in opportunities per million units for convenience: Processes that are considered highly capable are those that experience only a handful of defects per million units produced. DPMO differs from reporting defective parts per million (PPM) in that it comprehends the possibility that a unit under inspection may be found to have multiple defects of the same type or may have multiple types of defects. Identifying specific opportunities for defects is an art.

$D P M O=\frac{1000000 * \text { number of defects }}{\text { number of units } * \text { number of oppertunities perunit }}$ 


\subsection{Sigma Level}

Based on the above results using the known values of DPMO or yield the sigma level can be calculated.

\section{Literature Survey}

Bowen \& Youngdahl (1998) reported that reduce the performance trade-offs make the value-added processes flow and implement customer driven system eliminate losses in the value chain of activities, from development to delivery Increase customer focus and involvement in the development and delivery processes empower employees and teams.

Swank (2003) reported that reduce the performance trade-offs make the value-added processes flow and implement customer-driven system eliminate losses in the value chain of activities, from development to delivery increase customer focus and involvement in the development and delivery processes empower employees and teams segregate activities by complexity publish/ present performance results.

Sánchez \& Pérez (2004) reported that limitation of losses continuous improvement multifunctional teams' just-in-time delivery involvement of suppliers Flexible information systems.

Ahlstrom (2004) reported that elimination of waste zero defects Pull instead of push multifunctional teams decentralization of responsibilities verticalized information systems continuous improvement.

Womack \& Jones (2005) reported that solve the customers problem completely by ensuring that all services operate and work together do not waste the customers time provide exactly what customers want provide what is wanted, exactly where wanted provide what is wanted, where wanted and when wanted.

Jones (2006) reported that to specify what creates and what does not create value from the customers' perspectives identify all the steps needed to design, order and produce the service along the flow to focus on losses that do not add value make those activities that create value flow without interruptions, return or fragments do only what is driven by the consumer strive for perfection, continuously improving services and value stream.
Sarkar (2007) reported that the application of the DEB-LOREX model showing all the organizations processes and ensuring sustainability. Use of five elements: people, processes, partners, troubleshooting and promotions.

Bicheno (2008) reported that the new wastes: making the wrong product to be efficient, human capital, inappropriate systems, energy and water and natural resources. Seven wastes in customer service: delays, duplication, unnecessary movement, lack of clarity in communication, wrong inventory, missed opportunities and mistakes. Fourteen office wastes: screening and research, inappropriate measurement, low load, high load, inappropriate prioritization, interference, inappropriate frequency, startup and end off, mistakes, errors or lack of appropriate knowledge, communication error, suboptimization, wait, improper presence and inappropriate tradeoff.

Y. Yadav et al (2011) reported that the implementation of $5 \mathrm{~S}$ in banks at Ajmer city there are three general purposes, exploratory, descriptive and explanatory, of carrying out research. The aim of this research work is to gain a deeper understanding of how to develop an environment that only includes the required items, effective working environment and eliminate hidden waste to improve the levels of safety and quality at the work place. A clean, organized and systematic workplace which directly reduces waste and thus impacts productivity, quality, costs. It concludes that $5 \mathrm{~S}$ is an approach to achieving world class status.

A.M. Văduva (2011) reported that in this study shows how to address change and how to implement lean in different parts of the business. Special emphasis has been given towards $5 \mathrm{~S}$ implementation in the banking sector.

\section{Methodlogy}

The usage of methodology is to identify where the bottle neck "wastes" are happening in the service center, develop an initial frame work to address the issues in service center.

DMAIC $\Rightarrow$ DEFINE, MEASURE, ANALYZE, IMPROVE AND CONTROL 
Each step in the cyclical DMAIC Process is required to ensure the best possible results. The process steps:

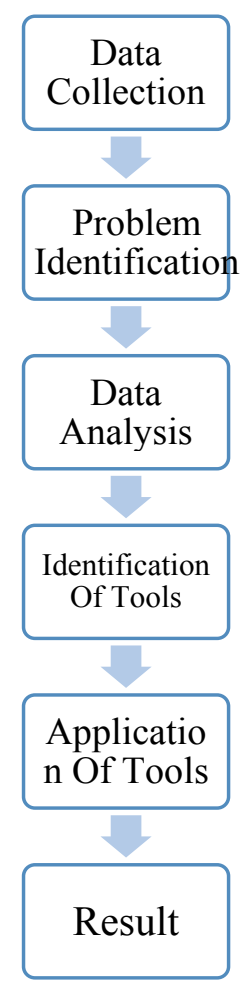

Figure 4. Process flow.

\subsection{Data Collection}

\subsubsection{Arrival of the Vehicle}

The bike arrives at the entrance of the plant. Here, a Service Advisor is allotted to that bike, who registers the customer's complaints, if any, into a logbook, known as a Job Card. A test drive is conducted, along with the customer to identify run-time issues with the bike. The technical problems are explicitly jotted down in the job card and an estimated delivery time is notified to the customer. A supervisor oversees the operations that the bike undergoes, during its time in the plant.

\subsubsection{Washing}

The bike to be serviced is sent to the first stage wash. This serves two purposes: i) scratches and dents made prior to the servicing of the bike can be known; ii) since the whole body of the bike is washed free of dirt, servicing can be performed with considerable simplicity.

\subsubsection{Drying}

Washed bike are dried with a high velocity jet of air to speed up the evaporation process. The body and interiors are then wiped with a clean cloth to completely remove remnants of water and dust particles

\subsubsection{Process at Bay}

The next step is taking the bike to an available bay for processing. For that requiring oil replacement, the bike is lifted up using hydraulic ramp to expose the underbody. Once that is done, other functions like wheel removal, repair of axle and leak checking can be performed with relative ease.

\subsubsection{Inspection}

The processed bikes now need to be scrutinized for errors. Accordingly, the inspectors are assigned to check for the blunders that might have been overlooked during the process at the bay. A second test drive may be conducted if major repairs have been performed; which also necessitates the second-stage wash.

\subsubsection{Dispatch}

Finally, after the inspector's consent, the bike is all set to be delivered to the customer by the agreed upon time limit. The customer's billing and transaction takes place in the office.

\subsection{Problem Identification}

In average there are 50 vehicles are arriving regularly to service center. In that only 40 to 45 vehicles can be delivered within a day. An inventory of 5 vehicles per day are dumped into service center the same process takes place day by day and hence inventory raised up gradually. So that they should allocate extra working hours to control inventory. It was the main problem faced in service center

Table 2. Timing of process

\begin{tabular}{|l|l|}
\hline Process & Time taken(min) \\
\hline $\begin{array}{l}\text { Arriving of vehicle into service } \\
\text { center }\end{array}$ & 20 \\
\hline Washing & 20 \\
\hline Drying & 15 \\
\hline Process at the bay & 104 \\
\hline Inspection & 20 \\
\hline \multicolumn{1}{|c|}{ Total } & 179 \\
\hline
\end{tabular}

\subsection{Identification of Tools}

The tools to be used are identified by using fishbone diagram. 


\subsection{Cause and Effect Diagram}

The Cause and effect diagram is also called as a fishbone diagram or Ishikawa diagram shown in Figure 5. It is a visual tool to categorize potential causes of the problem to identify its root causes.

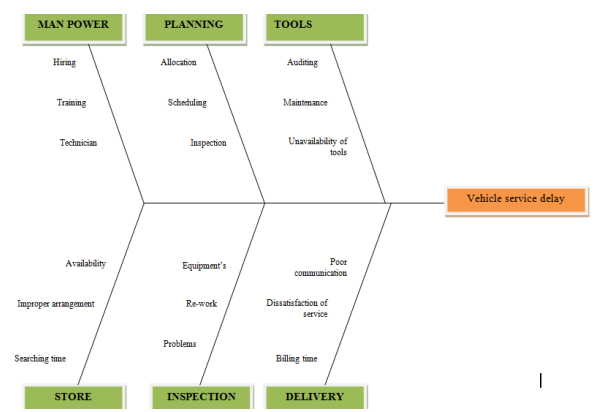

Figure 5. Fish Bone Diagram.

The main reason for the vehicle service delay is predicted by using the fishbone diagram, they are six reasons mention below.

Manpower: Improper training, Hiring unskilled labor, Insufficient technicians.

Planning: improper (allocation, scheduling, inspection).

Tools: The auditing of the tool is not having a continuous manner, Maintenance of the tool improper, Missing of the major tool and special tools.

Store: Maintaining the improper arrangement, Make sure of the availability of the tools.

Inspection: Unskilled labor, Improper verification, Not providing with the proper specification of the inspection tool.

Delivery: The customer should wait for the billing, Poor communication between the customer and advisor, And dissatisfaction with the service due to customer's voice.

\section{Implementation of Tools}

\section{$4.15 \mathrm{~S}$}

In Japanese, $5 \mathrm{~S}$ is the short form of five words which present the concept of good maintenance.

The definitions and significance of the five words are given below:

\subsection{Sort}

The first step in the process is known as "Sort". It is getting eliminated by what is not needed. Unnecessary items are removed from the work area. All incomplete work is completed or removed from the area. Items which require repairs and replacement are segregated. All work areas, cabinets and drawers are cleaned, organized and labeled. The main motto is to "Separate needed items from unneeded items by sorting through items and disposing of rarely used items"

\subsection{Set in Order}

The second step is called "Set in order" or "Straighten" which means to put the things which are required in specific position. There has to be "A place for everything and everything in its place." Straighten involves locating the items in the order of flow. All work areas, storage areas and

Equipment are clearly decided and well organized. Standard information boards are established for data management so that the success of the changes can be verified. The main motto is to "Arrange the remaining items to be most efficient and usable following the process flow by organizing and labeling item locations"

\subsection{Shine/Scrub}

The third step is known as "Shine" or "Scrub" which means to "Maintain the work space for the already sorted and set in order items by cleaning the workspace". Scrub is the cleaning portion of the checklist. All the working areas are cleaned.

\subsection{Standardize}

"Ensure flexibility across all users by developing procedures to preserve and monitor the first three 5S." It is meant to standardize procedure and best practice in the workplace so that the standards are completed (documented) and ensuring that they are strictly adhered to.

\subsection{Sustain}

"Making a nature of properly maintaining correct procedures." The last and the most difficult of the $5 \mathrm{~S}$ is sustain. Standard work guidelines and standard cleaning work procedures are followed. Emphasis is given as to how the set, instructions and guidelines are followed through routine inspection. It leads to increase in awareness among the employees, decrease of errors and wastage, improvement in communication among staff and human relations. 


\subsection{Common Ways of Resistance to 5S}

It has been generally noticed that, at the moment the organization decides to implement the Kaizen concepts are shown in Figure 6. The personnel shows resistance to change and the most frequent motivations will be the following:

- What is so special about sorting and arranging?

- Why should we clean since it gets dirty again?

- Sorting and arranging will not increase the results.

- We have already implemented order and cleaning.

- We applied 5S years ago.

- We are too busy to deal with $5 \mathrm{~S}$ actions.

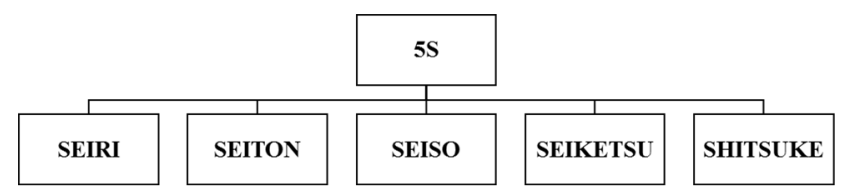

Figure 6. 5S.

\section{Implementation of $5 \mathrm{~S}$}

Before 5s:
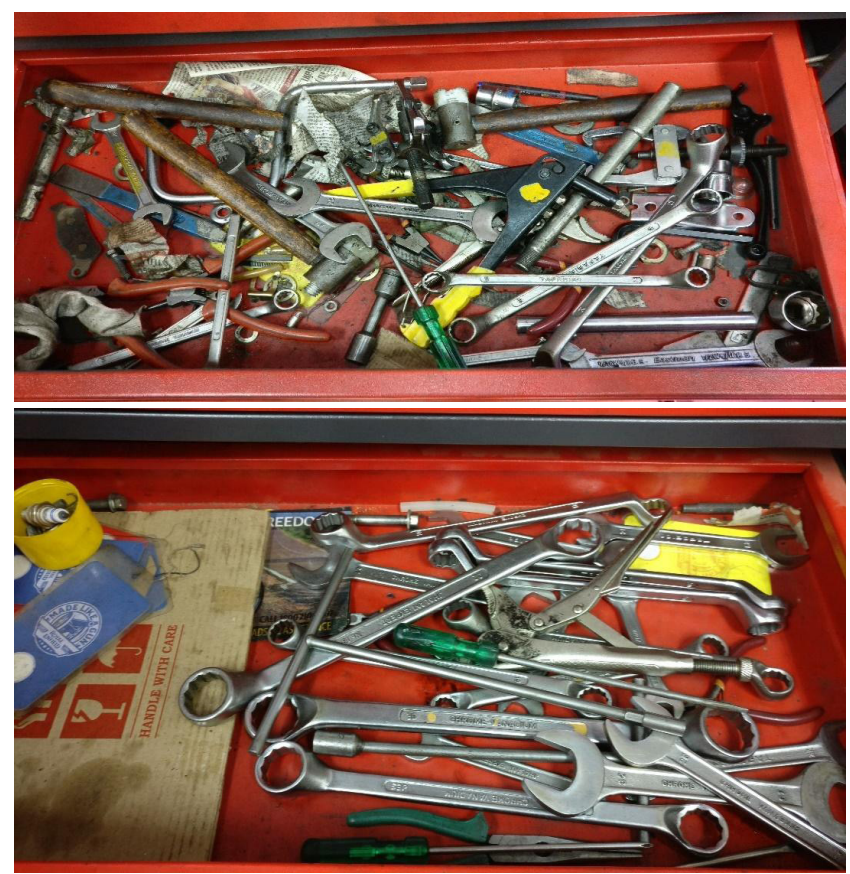

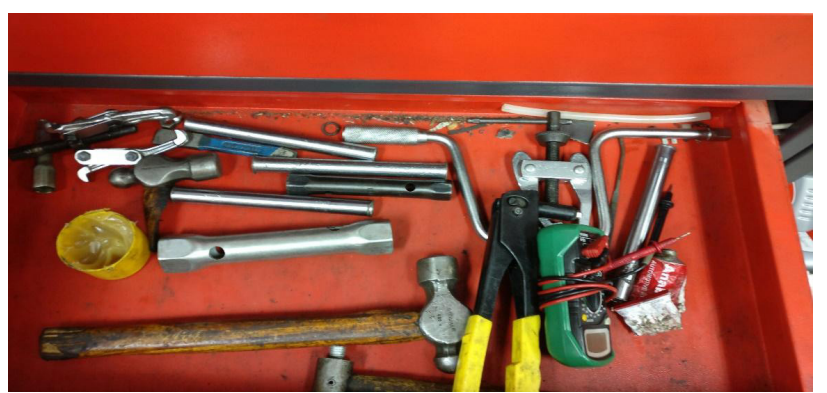

Figure 7.

\subsection{Value Stream Mapping (VSM)}

The ultimate goal of VSM is to identify all types of wastes in the Value stream and to take step to try and eliminate these. Waste can be a part of a process that takes time and resources but adds no value to the output. VSM has supporting methods that are often used in lean environments to analysis and design flows at the system level (across multiple processes).

Although value stream mapping is often associated with manufacturing, it is also used in logistics, supply chain, service related industries, healthcare, software development, product development and administrative and office processes.

In a build-to- suggests that the value-adding steps be drawnacrossthecentreofthemapandthenon-value-adding steps be represented in vertical lines at right angles to the value stream. Thus, the activities become easily separated into the value stream, which is the focus of one type of attention, and the 'waste' steps, another type. $\mathrm{He}$ calls the value stream the process and the non-value streams the operations. The thinking here is that the non-value-adding steps are often preparatory or tidying up to the value-adding step and are closely associated with the person or machine/workstation that executes that value-adding step. Therefore, each vertical line is the 'story' of a person or workstation whilst the horizontal line represents the 'story' of the product being created. Value stream mapping is a recognised method used as part of Six Sigma methodologies 


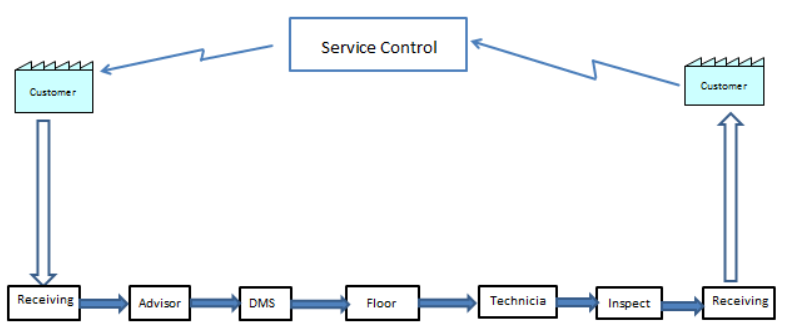

Figure 8. Layout of VSM.

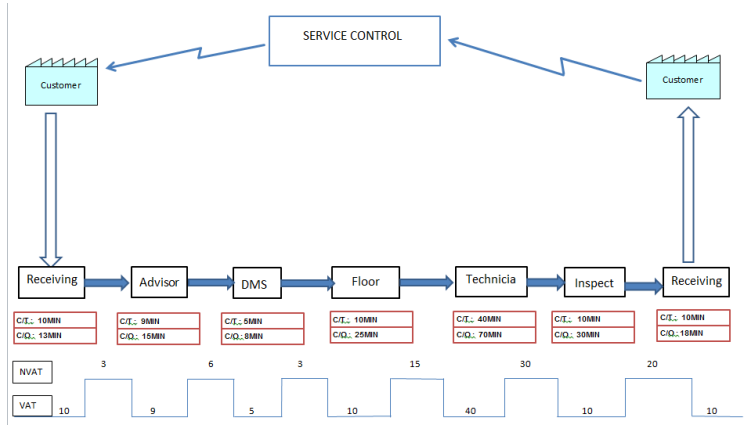

Figure 9. Current state VSM.

Total time $-179 \mathrm{~min}$

Value added time $-94 \mathrm{mins}$

Non value added time $-85 \mathrm{mins}$

\subsubsection{Five Guidelines for Value Stream Mapping}

Base the Value Stream Map process on customer requirements. You must understand what the customer values, and use that as your starting point. If you don't, you risk, in the words of my favorite band The Fall, paying "the highest attention to the wrong detail."

Capture the process as it operates now, not how it's supposed to operate.

A process that worked well when you had 20 employees may not perform as efficiently now that the business is a 200-person company. Be sure you map the process as it happens now, not the way it used to work-or how you wish it worked!

Assign a Value Stream Map manager to lead the mapping effort.

Input from team members and stakeholders is important, but appoint (or elect) one team member to draw the entire value stream map. This ensures that the manager understands the material and information flows.

Walk through the process to ensure that the flow of materials and information is accurate.
Make sure your map reflects the reality of the processverifying this by following the process from start to finish can reveal crucial details you might have missed.

Focus on one small step at a time. Make sure you capture each step accurately. For example, don't trust the clock on the wall to measure cycle times- use a stopwatch.

\subsection{Quality Function Deployment (QFD)}

Quality Function Deployment (QFD) is a method developed in Japan beginning in 1966 to help transform the Voice of the Customer [VOC]. The original developer, described QFD as a «method to transform qualitative user demands into quantitative parameters, to deploy the functions forming quality. QFD is applied in a wide variety of services, consumer products, and military needs.

Quality must be designed into the product, not inspected into it. Quality can be defined as meeting customer needs and providing superior value. This focus on satisfying the customer's needs places an emphasis on techniques such as Quality Function Deployment to help understand those needs and plan a product to provide superior value.

Quality Function Deployment (QFD) is a structured approach to defining customer needs or requirements and translating them into specific plans to produce products to meet those needs. The "voice of the customer" is the term to describe these stated and unstated customer needs or requirements. The voice of the customer is captured in a variety of ways: direct discussion or interviews, surveys, focus groups, customer specifications, observation, warranty data, field reports, etc. This understanding of the customer needs is then summarized in a product planning matrix or "house of quality". These matrices are used to translate higher level "what's" or needs into lower level "how's" - product requirements or technical characteristics to satisfy these needs.

\subsubsection{Things do in QFD}

Take the time to address conflicts in requirements Keep the amount of information at a manageable level. If one hundred customer needs are identified, and these were translated into an equal or even greater number of design requirements, there would be more than 10,000 potential relationships to plan and manage. 
Design for Lean Six Sigma is the logical next step for a company pursuing excellence in designing new products and services. Lean Six Sigma focuses on delivering both Lean speed and Six Sigma defect-free quality. Design for Lean Six Sigma takes the next step by focusing on new development to eliminate unwanted complexity, and deliver streamlined, customer-focused, defect-free services.

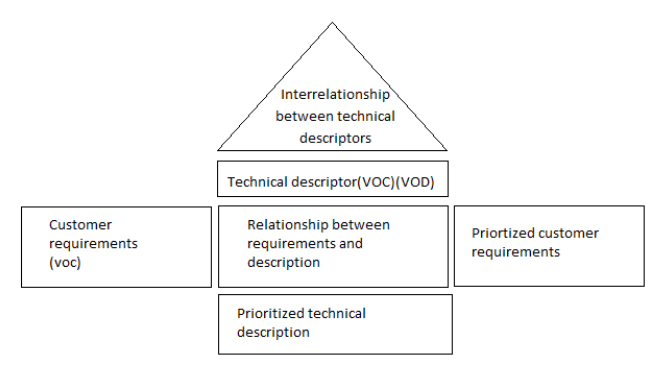

Figure 10. House of quality.

Every service has certain things that it must do in order to perform acceptably from a customer's viewpoint. Functional analysis breaks the service down into its key tasks solution ideas for each function, usually displayed in a tree diagram. Functional analysis also helps break down the problem into more manageable pieces to improve the odds of developing the best concepts.

In the Measure phase, the team developed the first House of Quality with QFD. Here, they continue working with the QFD matrix, completing House 2, which links the functions with the design requirements. The goal is to prioritize the functions that have the strongest link to the Voice of the Customer/Process Partner, because those will be the foundation of any new design. You can also use this work to flow down the high-level design targets into smaller design. In completing House 2, the team will understand what functions the product/service must have, and how those functions rate in priority. Now they will investigate how those functions can be filled. The secret here is to be as creative as possible:

\subsection{Brainstorm Ideas}

With a littlecreativity and planning up front, brainstorming can be both a great source of new ideas and a lot offend! There are many different twists on idea generation to help spark creativity within the team. If you are working on consumer services, visit places(such as local stores) where customers purchase or use the type of product or service you're designing or visit customer sites to observe similar services in use.

\subsection{Voice of the Customer}

1. I got an appointment for a week of my service date.

2. I had my choice of days.

3. I had my choice of time.

4. I was asked if there is an accident.

5. I was asked for the complaints.

6. The warranty claim was processed properly.

7. The insurance claim was processed properly.

8. My insurance organization coverage for the workshop.

\section{Result}
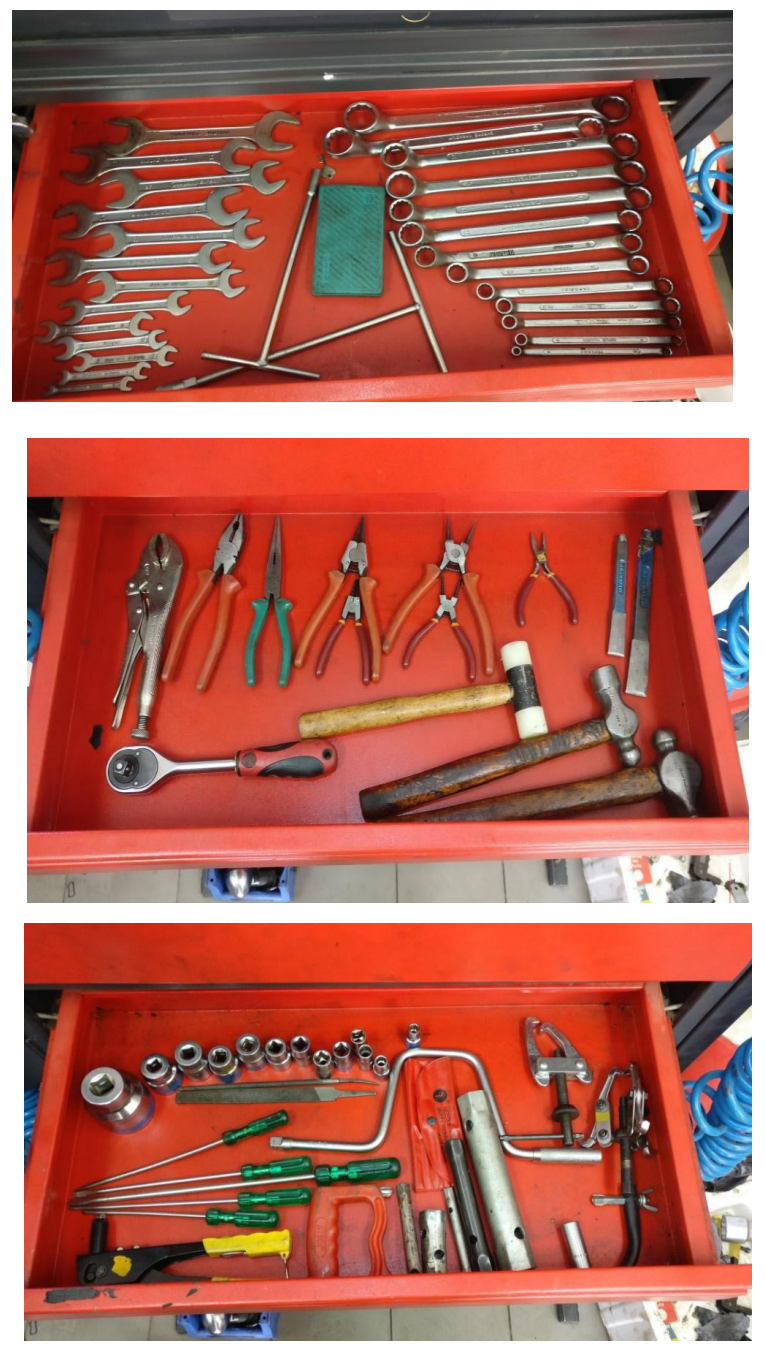

Figure 11. Application of 5S. 
After implementation of 5s methodology in the tool room the non-value added time is reduced to the maximum extent which is shown in future state VSM and also we implemented 5s methodology spares store which reduced the waiting time

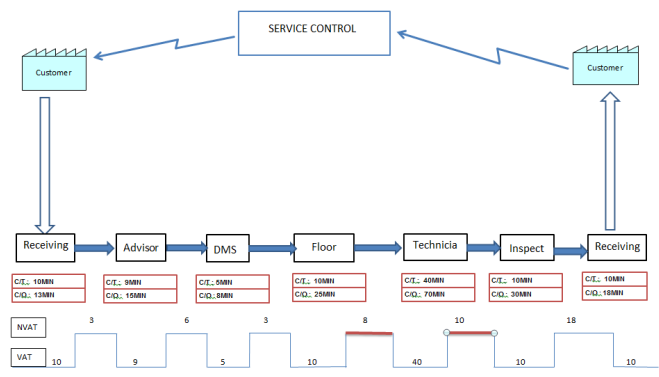

Figure 12. Future state VSM.

Total time- 142 minutes

Value added time- 94 minutes

Non Value added time- 48 minutes

In $\mathrm{t}+$ he Current State VSM:

Total time- 179 minutes

Value added time- 94 mintues

Non value added time- 85 mintues

The non-value added time is reduced from 85 minutes to 48 minutes due to the implantation of 5 s methodology and value stream mapping. By using the future status value stream mapping we have found the reduced the non-valued activities.

The increase in the efficiency of service center after implementation of lean techniques is $26 \%$. The delivery rate was 37 vehicles for a day and it is increased to 49 vehicles.

\section{Conclusion}

- The purpose of using LEAN tools was to gain customer satisfaction, higher quality service, eliminate all kind of wastes in service centre, reduce lead time, use fewer resources "staff, money, floor space ...etc."

- By using this three methodology (5S, Value stream mapping, Quality function deployment) in the service centre we reduced the lead time of service.
- The extra cost spent by the company is reduced.

- The future process is to apply the particular lean tool to improve the service timing by reducing the nonvalued added timing and also to increases the intake of bike for servicing in day-to-day today process.

- The company had spent a huge sum of money for the extra wages given to the workers for their overtime after doing this project the amount spent on extra wages is saved.

\section{References}

1. Kennedy and Brewer, 2007; Shah and Ward, 2003; Womack, Daniel and Roos, 1990; Womack and Jones, 1996)

2. Sugimori Y, Kusunoki K, Cho F, Uchikawa S. Toyota production system and kanban system: Materialization of just-in-time and respect for human system. International Journal of Production Research. 1977; 15(6):553-64. https:// doi.org/10.1080/00207547708943149.

3. Bhasin S, Burcher P. Lean viewed as a philosophy. Journal of Manufacturing Technology Management. 2006. https://doi.org/10.1108/17410380610639506.

4. Womack J, Jones DT, Roos D. The machine that changed the world. NY: Rawson Associates; 1990.

5. Hayes RH, Pisano GP. Beyond world class: The new manufacturing strategy. Harvard Business Review; 1994 Jan-Feb.

6. Shah R, Ward PT. Lean manufacturing: Context, practice bundles, and Performance. Journal of Operations Management. 2003; 21(2):129-49. https://doi. org/10.1016/S0272-6963(02)00108-0.

7. George ML. Lean six sigma. New Delhi: Tata McGraw Hill; 2002.

8. Lehtinen U, Torkko M. The lean concept in the food industry: A case study of contract a manufacturer. Journal of Food Distribution Research. 2005; 36(3):57-67.

9. Bhat S, Jnanesh NA. Transforming higher education with lean six sigma. HEF Indian Journal of Higher Education. 2013; 3(2):81-5.

10. Bhat S, Jnanesh NA, Melvyn RA, D'souza RA. Application of operations research technique to improve the performance of the HID of a hospital. Journal of Mechanical Engineering and Automation. 2015; 5(3B):81-3. 